\section{Parameter estimation: An estimated variance- covariance matrix for averaging model parameters in information integration theory}

\section{JAMES ZALINSKI \\ University of Califormia-San Diego, La Jolla, California}

The averaging model of information integration theory has found wide application in the study of human judgment. Extensive evidence has demonstrated its broad usefulness across many areas of psychology (Anderson, 1981). From initial applications in laboratory research, the averaging model has been employed in more general settings. Recent studies have extended the theory into applied decision research (Shanteau \& Phelps, 1977), applications of multiattribute judgment models (Zalinski \& Anderson, in press), and studies of marital interaction (Armstrong \& Anderson, 1984). A number of experimenters have used numerical techniques to estimate the averaging model parameters (e.g., Birnbaum \& Stegner, 1981; Leon, Oden, \& Anderson, 1973; Norman \& Louviere, 1974). By comparing the estimated parameters, quantitative conclusions can be drawn concerning the relative importance and value of the different stimulus dimensions.

Standard analysis-of-variance techniques exist for the statistical comparison of averaging model parameter estimates (Anderson, 1982). The practical value of these comparisons depends upon their statistical power. This power is a direct function of the variability of the data, in this instance the estimated parameters. In order to plan experiments capable of providing adequate power for comparisons among the parameters, it is important for researchers to have estimates of their variances before they finalize a design and gather data.

The present program provides a means for computing this statistical power analysis. When given as input specifications of an experimental design, parameter values, and the response error variance, the program provides as output an estimated parameter variance-covariance matrix. The researcher can use the program in a repetitive fashion, varying the experimental design, the values of the input model parameters, and the assumed error variance. Based upon the output variance-covariance matrices, the researcher should be able to determine an appropriate experimental design and sampling scheme for parameter estimation and comparison.

In the equal-weight case considered here, the judgment or response, $\mathbf{R}$, to a three-stimulus situation is represented as a weighted average:

This work was supported by National Science Foundation Grants BNS82-07541 and BNS82-12461 to Norman H. Anderson, principal investigator. The author's mailing address is: Department of Psychology, University of California-San Diego, C-009, La Jolla, CA 92093.

$$
\mathrm{R}_{\mathrm{ijk}}=\left(\mathrm{w}_{0} \mathrm{~s}_{\mathrm{o}}+\mathrm{w}_{1} \mathrm{~s}_{1 \mathrm{i}}+\mathrm{w}_{2} \mathrm{~s}_{2 \mathrm{j}}+\mathrm{w}_{3} \mathrm{~s}_{\mathrm{jk}}\right) / \Sigma \mathrm{w}+\mathrm{e}_{\mathrm{ijk}}
$$

Each stimulus is represented by a scale value, $s$, and a weight, $w$. The scale represents the value of the stimulus on the response continuum. The weight is the relative importance of the stimulus within the context of the judgment. The $e_{i j k}$ term represents the response error. Here the weight parameters are assumed to be constant for all scale levels within each stimulus dimension. The weights are normally required to sum to a constant, the condition necessary to define Equation (1) an averaging, as opposed to an adding, model. The $w_{0} s_{0}$ term represents an internal state variable representing the subject's initial belief or attitude concerning the experimental situation.

In the present application, it is assumed that the data will be gathered according to a three-factor design and that the data corresponding to each of the three two-way factorial subdesigns will also be obtained. The three twoway subdesigns are necessary to ensure identifiability of the weight and scale parameters (see Anderson, 1982, section 2.4.4). Finally, it is assumed that the response errors, $\mathrm{e}_{\mathrm{ijk}}$, will be independently and normally distributed and that the value of the response error variance is available.

The program uses the method of maximum likelihood and the Fisher information technique (Cramer, 1948; Edwards, 1972; Fisher, 1925). The estimated variancecovariance matrix is determined by computing the inverse of a matrix $M$, whose elements are minus the expected value of the second partial derivatives of the averagingmodel log-likelihood equation with respect to the weight and scale parameters:

$$
\left.m_{i j}=-E\left[\delta^{2} \text { LLE (averaging model) } / \delta \mathrm{P}_{1} \delta \mathrm{P}_{\mathrm{j}}\right)\right]
$$

Input. The user is prompted to input the number of stimulus levels within each of the three factors, the values of each of the weight and scale parameters, and a value for the response error variance.

Outputs. A summary output file is written to disk containing the labeled input parameters followed by the variance-covariance matrix for the full array of the weights and scales.

Accuracy. The accuracy of the variance-covariance matrices was checked by comparing them with results from Monte Carlo runs with identical parameters. Fifteen Monte Carlo runs were made (100 replications per run) while varying both the experimental design size and the values of the averaging model parameters. The designs were chosen to represent a broad range of experimental conditions, spanning those likely to be encountered in actual practice. The comparability of the variancecovariance matrices from similar Monte Carlo and Fisher information technique runs was good (see Zalinski, 1984).

Limitations. The program is currently written for experiments with complete data from a three-factor design, as well as with complete data from each of the three pos- 
sible two-way factorial subdesigns. Modifications to allow for a two-factor design or for missing data should be relatively straightforward. (Adequate constraint is available to ensure parameter identifiability with a twofactor design if data from the one-factor subdesigns are also obtained.)

Computer and Language. The program is written in F77 FORTRAN and has been implemented on a Prime 750 . It should be readily transportable to other systems with FORTRAN compilers. Logical unit assignments, however, may need redefinition for computers other than the Prime. As written, the program and data sections require $50 \mathrm{~K}$ bytes of memory. The program section itself requires $14 \mathrm{~K}$ bytes. Depending on the scope of the problem, currently large data arrays may be redimensioned to save memory.

Availability. A source listing of the program, sample input, and sample output are available from the author. Documentation is given in a header block and in comments in the program.

\section{REFERENCES}

ANDERSON, N. H. (1981). Foundations of information integration theory. New York: Academic Press.

ANDERSON, N. H. (1982). Methods of information integration theory. New York: Academic Press.
Armstrong, M. A., \& Anderson, N. H. (1984). Influence in marriage studied with information integration theory. Unpublished manuscript, University of California, San Diego.

Birnbaum, M. H., \& Stegner, S. E. (1981). Measuring the importance of cues in judgment for individuals: Subjective theories of IQ as a function of heredity and environment. Journal of Experimental Social Psychology, 17, 159-182.

Cramer, H. (1948). Mathematical methods of statistics. Princeton, NJ: Princeton University Press.

EDWARDS, A. W. F. (1972). Likelihood: An account of the statistical concept of likelihood and its applications to scientific inference. Cambridge: The University Press.

Fisher, R. A. (1925). Theory of statistical estimation. Proceedings of the Cambridge Philosophical Society, 22, 700-725.

LeON, M., Oden, G. C., \& ANDERson, N. H. (1973). Functional measurement of social values. Journal of Personality and Social Psychology, 27, 301-310.

Norman, K. L., \& LOUviere, J. J. (1974). Integration of attributes in bus transportation. Journal of Applied Psychology, 59, 753-758.

Shanteau, J. C., \& Phelps, R. H. (1977). Judgment and swine: Approaches and issues in applied judgment analysis. In M. F. Kaplan \& S. Schwartz (Eds.), Human judgment and decision processes in applied settings. New York: Academic Press.

ZALINSKI, J. (1984). Parameter estimation for the averaging model of information integration theory. Doctoral dissertation in preparation. University of California, San Diego.

Zalinski, J., \& ANDERSON, N. H. (in press). Measurement of importance in multiattribute judgment models. In J. B. Sidowski (Ed.), Condition, cognition, and methodology: Contemporary issues in experimental psychology. Hillsdale, NJ: Erlbaum.

(Revision accepted for publication December 3, 1984.) 